\title{
Research on Primitive Business Information Communication
}

\author{
Jing Huang \\ Postdoctoral Research Station \\ Jiang xi University of Finance and Economics \\ Nanchang, China
}

\begin{abstract}
Based on the "Field Theory", the thesis carries out the argumentation on the formation and communication of business information in the primitive society and agricultural society from the perspective of historical development. The formation and communication of business information are the inevitable result of the social development of human being, as well as the carrier and witness of the development of human civilization.
\end{abstract}

Keywords—primitive society; agricultural society; business information; communication mode

\section{INTRODUCTION}

The existence of the phenomenon is inseparable from the surrounding environment. Environment plays an important role in the coming into being, development, decline and dying out of things. This thesis introduces the "Field Theory" to further analyze the reas on for the existence of the phenomenon more accurately fro $m$ the existing environment of phenomenon. According to Bourdieu, "We define a field as a network or a structure of the objective relationship between positions." 1 "From the perspective of analysis, a field can be defined as a network or a structure of the objective relationship among all kinds of positions. It is because of the existence of these positions and the decisive factor they enforced on the actor occupying the given position or above the agency that these positions should be given more objective definition, which is based on the actual and potential situation of the distribution pattern of these positions within different types of power (or capital), and the objective relationship (compliance relationship, corresponding relationship, dominance relationship) with other positions and so on." 2 This kind of network or structure is not only the definition of a certain scope of the material world, but also contains the collective human consciousness and spiritual world that has the same structure and co-growing with the material world. Field provides the material and spiritual foundation to the certain (single) human social activity, becoming the important factor for the coming into being of this activity.

\section{II. “FIELD” IN THE PRIMITIVE AND AGRICULTURAL SOCIETY}

Primitive society was the initial stage of human society development, and also the umbrella name of the first stage of community activity after human was separated from the great apes pedigree during the evolutionary process. Paleolithic period was the original stage of human society development, which had stepped over the Pliocene epoch and Pleistocene epoch from the angle of climatology. According to the data collected by Mark Lynas, the overall environment of the Pleistocene epoch was described as "continuous El Nino phenomenon, south Pacific Ocean trade wind weakened until the wind direction changed to the east, hot air raised around Peru, warm current spread from west Pacific Ocean and India Ocean to east Pacific Ocean and other El Nino phenomenon." 3 It was due to this kind of climate change that made it possible for human to migrate to the new habitat field where cannot be reached before because of ice blockage. At the same time, the extinction of giant animal has reduced the survival risk of human, which also became an important factor of the increasing number of human reproduction. Under the optimized external environment, human was able to survive and expand in the primitive group gathering living mode and gradually separated from ape group. During this period, human food was mainly from hunting and collecting. Therefore, the major members of the primitive group were the collector and hunter. The individual subconscious of drawing on advantages and avoiding disadvantages affected individual action that the individual tended to join in a group to ensure a much longer survival time.

Primitive society was the first important stage of human society development. Under the primitive natural environment and human ethic group being based on blood relationship were the field characteristics of the primitive society. Members of the ethic group were in a state of adapting to nature and striving to survive. The motivation of production activity in the primitive society was to satisfy the surviving needs, and the production mode was mainly hunting and collecting. During the primitive society, the production materials were in public ownership, and the labor relations were the relations of equality and mutual assistance. At the same time, commodity has not come into being, and consumption things were equally distributed.

The change of productivity was the major impetus driving the development from the primitive society to the agricultural society. The change of means of production has promoted the revolution of the major social structure. Taking plough as an example: before the invention of plough, the farming tool was hoe, which was small and light that a single woman has the 
power to fin ish the production. Women engaged in collection and primitive agriculture, prepared daily cloth and food and were responsible for housekeeping, played an important role in the social and economic activities. After the invention of plough, the weight of production tool exceeded the power of a single woman, the increasing requirement on power in production activity made men gradually becoming the center of production, and thus forming the patriarchal society. Along with the improvement of productivity, agriculture, handicraft industry and metallurgic industry all became the economic agents of the agricultural society. Among them, the best representative is the independent planting of commercial crop in agriculture. The independence of commercial crop from the traditional crops marked the maturity of agricultural society. Commercial crop is the productive material of textile and oil industry, which independence marked the completion of the dividing of agricultural society, and the further improvement of human towards the needs of material life (from the need of survival to the need of food and clothing, and to the need of clothing type and color and food type), as well as formed a relatively complete commod ity circulation system.

\section{THE COMMUNICATION MEDIA SYSTEM OF THE PRIMITIVE AND AGRICULTURAL SOCIETY}

According to Engels, labor is the basic reason driving the evolution from ape to man. Labor separated the function of hand and foot and promoted the evolution of hand. The function of hand evolved to make tools and grow crops from the original supporting and stabilizing. The living of apes had moved from trees to land and from forest to the flat area gradually. The appearance of ape body had also changed from crawling to walking and standing. The lower limbs began to grow sturdy and strong, and the function of lungs and throat were also increased due to walking upright. Changes to the muscles surrounding the vocal cords produced clear syllables. More importantly, labor had promoted the formation of hu man consciousness, and the differentiation of the intuition thinking and abstract thinking. Human began to transform nature consciously. As the initial stage of human society development, the media systems of primitive society were also primitive, mainly physiological systems of the body. Human physiological media was divided into incoming media channel and output media channel, which are the visual system, auditory system, language system and body language system. It may also be divided into language communication and nonlanguage communication.

Incoming media channel includes visual system and auditory system. Human auditory system is mainly composed of eyeball and visual neurons. Photoreceptor cells within eyeball receive the magnetic stimulation of $370-740 \mathrm{~nm}$. Light is reflected on the retina by the lens and vitreous of the eye, and enters the cranial cavity through the cone cell, rod cell, bipolar cell and ganglion cell, and finally reaches optic center to be perceived and recognized by human. Human auditory system is composed of three parts, namely the external ear, the middle ear, and the inner ear. Sound wave is collected by the auricular of external ear and is transmitted to eardrum. After the vibration of eardrum, the sound wave reaches three otosteon of the inner ear through the transmission of the middle ear. After receiving the signal, the auditory nerve endings of the inner ear transmit the signal to the auditory center of the brain cortex through auditory nerves, and thus sound is perceived and recognized by human.

Output media channel includes the language system and body language system. The language system mainly includes vocal organs and language center system. Vocal organs include respiratory organs (diaphragm muscle, lungs, thorax, trachea and bronchus), resonance and vibration organs (throat, tonsil, nasal cavity, oral cavity, and laryngeal cavity), and vocal organs (vocal cords, glottis, lips, tongue, and teeth). Language center is mainly in the left hemisphere, including Broca's area (language regulation mechanism: the using of conjunction, verbal and complex sentence, and the coordinate exercise of facial vocal organs and muscle), Wernicke's area (in charge of phonological detection and understanding word meanings), and angular gyrus (in charge of grammar and spelling rule). Highly coordination of language center and vocal organs: first, expiration of the respiratory organ, closing and vibration of laryngeal vocal cords to produce sounds, resonance through throat, nasal cavity and oral cavity, and producing human language with the movement of tongue and teeth. Due to the differences of each individual vocal organ, everyone has the different timber. The size of sound is related to airflow and vocal cavity, and the tone is related to the thickness and tension of vocal cords.

Auditory system and language system belong to phonological communication. Visual system and body language system belong to non-phonological communication. Before the come into being of characters, picture had undertaken the responsibility of recording history. Cliff painting in the primitive society was the painting with the nature of language. As the major media of information communication, the primitive cliff painting contained various ways of human sensing nature, such as visual sense, auditory sense, touch sense, smell sense, taste sense and so on. Body language was also an important part of cliff painting recording. Body language communication took an important position in the history of human information communication. During the primitive society when human cannot express the complete, complex and logic meaning, body language had become the media assisting phonetic representation naturally. Mehrabian, an American psychologist, had proposed a famous equation: the overall human information expression $=7 \%$ language + $38 \%$ sound $+55 \%$ body language. From the equation, we can see that body language still occupies an important position in modern human communication.

\section{COMMODITY INFORMATION COMMUNICATION} CHARACTERIST ICS IN PRIMITIVE AND AGRICULTURAL SOCIETY

The origin of commodity began with exchange. Exchange as gift was the important way of establishing alliance relationship with others. It was later changed into barter transaction, such as sickle for sheep, coptis chinensis for cow and so on. Since then, taking cow as the money equivalent had became mutually accepted convention. In Tibet, the custom of taking the number of cow as the standard of household wealth still exists. Along with the deepened social division of labor, handicraft industry was separated from agriculture. Social 
division of labor made it possible for the individual to be more concentrated into production relying on his own advantages, and thus the individual was freed from the social living condition of self-sufficient. However, the individual needs are various. In order to get all kinds of material goods, goods produced should be put into the exchange process of commodity economy. Small commodity economy was the characteristic of commodity economy at this time. From the objective factors, productivity during this period was limited by the restriction of area, custom, economic environment and so on. From the subjective factors, the major aim of commodity production in this period was to meet self needs, and the surplus part was taken to exchange to supplement and enrich the present living standard. There was no motivation of getting profits from commodity exchange.

The separation of handicraft industry form agriculture marked the development of commodity economy. Merchant came into being as the important media of commodity economy. Along with the increasing of the frequency and times of exchange, professional middle man who engaged in exchange emerged at the right moment. The rising of merchant formed the third social division of labor, laid the essential condition of commodity information communication in primitive and agricultural society. In primitive and agricultural society, the material conditions for fulfilling the exchange of two goods included two goods A and B, currency and contract, and the psychological condition was the willingness of exchange of the possessors of goods $\mathrm{A}$ and $\mathrm{B}$. The result of commodity information communication was to obtain information reflection and finish the commodity exchange at the same time.

The carrier and channel of information communication is the merchant. The merchant carries the interpersonal communication to the possessor of goods $\mathrm{A}$ of the information of goods $\mathrm{B}$, and then carries the interpersonal communication to the possessor of goods B of the information of goods A. When the two possessors receive the information, they can decide whether they are going to finish the exchange according to the information and their own needs. What calls for special attention is that the merchant carefully and specially chose the target of information communication during the process according to his own professional advantage and the mastery of market. The target custom fulfils two factors, relatively high price and less decision-making time. At the same time, secondary processing of the commodity information is made according to the market. What is notable is that the reprocessing of the merchant towards commodity information is invisible. The merchant will fin ish the information processing on his own with no fixed basis and principle, completely relying on his self professional quality. The communication at this stage is word to ear communication, also called face to face communication or interpersonal communication. In the primitive and agricultural society, the initial commodity information communication mainly has the following characteristics:

- The information sender and receiver were in the same space and time. If the goods A and B were in different time and space, the exchange could not be finished. The sender and receiver took two people as the subjects. The media systems of the information sender and receiver were complete, (with complete auditory and visual system). The communication was mutual and information reflection was in time.

- The information sender and receiver obtained the symbol system that being familiar with both sides. The signifier and signified in their symbol systems were roughly corresponding, conforming to the socially accepted norms of the two. The commodity information communication in the primitive society referred to that the two sides have the same or similar language, with the characteristics of strong situational communication.

- The commodity communication was based on spontaneity of communication and meeting the needs. Word to ear communication is the communication stressed on time, memory and the exercise of verbal expression. Receiving the verbal expression training and good memory were the important market competitiveness. Word to ear communication was limited by time, and the characteristics of low information accuracy, bad logic and statement doesn't tally with the facts have affected the commodity exchanges.

- Word to mouth communication was the signify communication, with the features of liner communication, which was greatly affected by the field and with a strong sense of feeling within the field. When there was change in the field, the social culture changed and the liner communication might not be able to continue.

- Because of the instantaneity of commodity communication in the primitive and agricultural society, word to ear communication was restricted by time. That is to say, the commodity information would disappear during the communication process and would not be stored in a media channel.

\section{CONCLUSION}

To sum up, the communication of primitive business information is based on interpers onal communication, which is the most important in communication. The communication motive is based on satisfying the mutual social needs. The primitive business information communication is the starting of business information communication. The characteristics of face to face communicaiton have become the important foundation of business information communication in the new media era.

\section{REFERENCES}

[1] L.D Wacquant, Towards a Reflexive Sociology : A workshop with Pierre Bourdieu[J], Sociological Theory, Vol7.1989:P39.

[2] Bourdieu, Wacquant. Practice and Introspect [M] Beijing: Central Compilation and Translation Press. 2004:P134.

[3] National Geographic Channel, Six Degrees Could Change The World, Mark Lynas interview. Retrieved February 14, 2008. 